\title{
O OCIDENTE DIVIDIDO: O IMPACTO DA GLOBALIZAÇÃO ECONÔMICA NEOLIBERAL NA INTEGRAÇÃO POLÍTICA DA UNIÃo EUROPEIA*
}

\author{
[THE DIVIDED WEST: THE IMPACTS OF THE NEOLIBERAL ECONOMIC GLOBALIZATION IN THE \\ EUROPEAN UNION POLITICAL INTEGRATION]
}

\author{
Jorge Adriano Lubenow** \\ Universidade Federal da Paraíba
}

\begin{abstract}
Resumo: Este artigo organiza de modo temático as análises críticas de Jürgen Habermas sobre impactos da globalização econômica na integração política europeia (tais como as consequências visíveis da diminuição do Estado e a loucura das privatizações), das possibilidades da Europa funcionar como um contrapoder ao unilateralismo americano, e do fim do otimismo político diante da ausência de uma política externa europeia. De acordo com Habermas, o processo de unificação europeia, além das dificuldades internas em ir além da integração econômica, da ausência de uma integração política comum e da indefinição quanto a finalidade da unificação, mostraria também a ausência de uma política externa comum, enfraquecendo a posição da Europa diante do fim da ordem mundial bipolar e do unilateralismo hegemônico norte-americano. No entanto, embora a União Europeia devesse trabalhar a voz política no cenário da política externa para redefinir seu papel global, um contrapoder europeu estaria longe de se tornar realidade.
\end{abstract}

Palavras-chave: Jürgen Habermas; Globalização econômica; Política europeia; Ceticismo
ABSTRACT: This study thematically organizes the critical analysis of Jürgen Habermas on the impacts of the economic globalization on European political integration (such as the visible effects of the decline of the state and the insanity of privatizations), the European possibilities to act as a counter-power to American unilateralism, as well the end of the political optimism because of the absence of a European foreign policy. According to Habermas, the process of European integration, in addition to the internal difficulties in going beyond economic integration, the absence of a common political integration and uncertainty about the purpose of unification, also shows the absence of a common foreign policy, weakening European position face to the end of the bipolar world order and of United States hegemonic unilateralism. However, while the European Union should work the political voice in the foreign policy arena to redefine its global role, a European counter-power would be far from becoming reality

KEYWORDS: Jürgen Habermas; Economic globalization; European policy; Scepticism

* Este artigo é parte de pesquisa de pós-doutorado/CAPES sobre democracia transnacional em Jürgen Habermas realizada junto a Europa-Universität Flensburg no semestre de inverno 20142015, sob a orientação do Prof. Dr. Hauke Brunkhorst. Uma versão preliminar foi apresentada na disciplina "Transnational Democracy Europe and beyond", coordenada pelo mesmo professor. ** Pós-Doutor em Filosofia. Professor de Filosofia do Departamento de Fundamentação da Educação e do Programa de Pós-graduação em Filosofia da Universidade Federalda Paraiba (UFPB).m@ilto: jlubenow@hotmail.com 
20 anos depois, acabou o otimismo político europeu. Ach, Europa, hoje é apenas o som suspirando. ${ }^{l}$

O que mais inquieta é a injustiça social gritante que consiste no fato de os custos socializados do malogro

do sistema atingirem de maneira mais dura os grupos sociais vulneráveis; é um escândalo político [...]

Eu espero que a agenda neoliberal não seja mais levada a sério, que seja dispensada. É preciso rever

esse programa todo de sujeição inescrupulosa do mundo da vida aos imperativos do mercado. ${ }^{2}$

\section{A DEMOCRACIA Pós-NACIONAL: A FRAQUEZa da União Europeia}

$\mathrm{N}$ a discussão sobre democracia pós-nacional, Habermas diferencia ao menos quatro posições: eurocéticos (que entendem a introdução do euro como precipitada), pró-mercado (que comemoram a moeda unificada), eurofederalistas (que buscam transformar os contratos internacionais em constituição política como meio legitimador das decisões supranacionais de comissões, conselhos, tribunais e parlamento europeus), e cosmopolitas (que vislumbram o Estado confederado da Europa como base inicial para a construção de uma "política interna mundial") ${ }^{3}$. A opção da União Europeia por uma "Europa-mercado" de formato neoliberal tem como consequência, segundo Habermas, a incapacidade das instituições da União Europeia para corrigir positivamente o mercado e impor regulamentações redistributivas: "Hoje atingiu-se um ponto no qual a densa rede horizontal que perpassa o mercado é complementada por uma regulação política relativamente fraca, e esta, por sua vez, por serviços públicos ainda mais parcamente legitimados"4. Em contrapartida, é preciso que os cidadãos europeus sejam reconhecidos não apenas pelo passaporte comum, mas como membros de uma mesma comunidade política. Também as políticas de redistribuição devem assentar numa formação democrática em termos europeus. Para tanto, o fundamento da solidariedade cívica deve estender-se para o âmbito europeu. A expansão da capacidade de ação política deveria andar paralelamente a uma expansão da base legitimadora das instituições europeias. No entanto, as condições de formação de um procedimento de legitimação democrático pós-nacional, que brote da sociedade civil e que encontre ressonância numa esfera pública europeia, ainda não foram satisfeitas $^{5}$. Em contrapartida, Habermas mantém a expectativa diante da hipótese derrotista (a impossibilidade de uma solidariedade civil pós-nacional), invocando o recurso histórico das condições artificiais de formação da consciência nacional, e a continuidade desse processo de aprendizado da identidade coletiva operado pelo impulso abstrato de transformação da consciência nacional e democrática, mas agora voltado para uma consciência europeia ${ }^{6}$.

Quem deveria controlar uma união política Europeia? Esta pergunta feita por Habermas na obra Era das transições, de 2003, trata de um ponto bem delicado: "A União Europeia entrou decididamente num processo de transição, tendo como alvo uma configuração política mais ampla e sólida. Porém, não consegue concretizá-la" ". Para resolvê-la, Habermas sugere: uma Constituição, sistema europeu de partidos, a formação de uma esfera pública, desenvolvimento de associações, iniciativas e movimento de cidadãos que ultrapassam os limites nacionais, o inglês como segundo idioma comum, a comunicação através dos meios de comunicação de massa pode 
desempenhar papel importante como "comporta". No entanto, Habermas observa com cautela "não estar iludido acerca de uma esfera pública na qual os meios de comunicação comercializados dão o tom"8; "os imperativos dos índices de audiência não deveriam infiltrar-se nos poros da comunicação cultural"" . Necessidade de constituição discursiva da esfera pública.

\section{A Europa em transição. CoOrdenadas em relação aO futuro}

Na obra Era das transições (2003), capítulo 6, Habermas trata do ceticismo com relação à Europa dos mercados. Nos desdobramentos de constituição de uma União Europeia emerge uma contradição: a criação de instituições políticas (organismos de Bruxelas, Suprema Corte Europeia, Banco Central Europeu) não significa necessariamente a garantia da legitimidade democrática e a consolidação da democracia política. A Europa encontra-se interligada pelo mercado e com pouca interferência político-administrativa, os Estados-membros cederam a soberania monetária para uma instituição e, com isso, perderam a capacidade de influenciar na economia. Por conseguinte, surge o problema de como resolver ou compensar as desigualdades sociais especialmente nos países economicamente mais fracos, uma vez que nesses países os sistemas de seguridade social ainda se encontram sob a regulação dos Estados nacionais. Por isso, a Europa encontra-se diante do dilema: resolver o problema pelas vias do mercado ou politicamente, tentando harmonizar gradativamente questões sociais, mercado de trabalho e política de impostos. Apenas pela segunda via a União Europeia criaria vigor político para determinar resoluções capazes de corrigir o mercado e organizar dispositivos com efeitos redistributivos.

Diante desse problema, diagnostica Habermas, os que simplesmente defendem a globalização (neoliberais) e os que simplesmente são contra (nacionalistas) não teriam dificuldades em apontar a saída. Enquanto os neoliberais se satisfazem com uma união monetária, os nacionalistas se utilizam de mecanismos de proteção e exclusão. Contrariamente, os partidários da versão defensiva da terceira via (federalistas) pretendem fazer da Europa uma federação transformando os contratos internacionais em constituição política como forma de assegurar legitimidade. No entanto, diferentemente das três posições acima, os partidários da versão ofensiva da terceira via defendem uma visão cosmopolita, partindo da constituição de um Estado europeu confederado, e desenvolvendo mecanismos transnacionais capazes de organizar e coordenar uma política interna, sem a necessidade de um governo transnacional ${ }^{10}$.

Para o filósofo frankfurtiano, o que mais chama a atenção nos neoliberais, nos nacionalistas céticos e nos federalistas é que todos duvidam da possibilidade de uma organização política democrática europeia apoiada no direito. No entanto, salienta Habermas, não há motivos para esse derrotismo; ${ }^{11}$ ainda resta o recurso que serviu de fundamento para a constituição das primeiras formas modernas de identidade coletivas: o impulso abstrato de formação da consciência e da solidariedade civil nacional. Escreve Habermas:

Ora, se essa forma artificial de uma "solidariedade entre estranhos" se deve a um impulso abstrator, histórico, que leva de uma consciência local e dinástica a se transformar numa consciência nacional e democrática, por que não admitir que um processo de aprendizagem semelhante poderia ser prosseguido para além das fronteiras nacionais? ${ }^{12}$

Apesar das dificuldades, apresentam-se como possibilidade: a organização de um Estado europeu federado (embora não nos mesmos moldes de funcionamento dos 
Estados nacionais), um sistema partidário europeu, esferas públicas nacionais interligadas no âmbito europeu, uma sociedade civil europeia (com grupos de interesses, organizações não-governamentais, iniciativas civis), sistemas educativos capazes de garantir uma segunda língua comum, entre outros, com o objetivo principal de mudar o curso em direção de uma política interna, capaz de superar as fragmentações sociais e das estratificações da sociedade, e conferir um fundamento legitimador do ordenamento político democrático europeu.

No caso de uma Constituição europeia, sublinha Habermas no capítulo 7, ("Será que a Europa precisa de uma Constituição?"), sem desconsiderar a discussão em curso, essa não seria a via correta capaz de resolver os problemas. A questão central não seria encontrar algo novo, mas manter as grandes conquistas do Estado nacional estendendoas para o âmbito pós-nacional. Nova seria apenas a instituição que resultará ao final desse percurso. Seria preciso preservar, mesmo no âmbito além-fronteiras, as conquistas do Estado de direito nacional, tais como as garantias materiais de vida, as chances de formação e lazer, os espaços sociais que conferem autonomia privada, os mecanismos de participação democrática, entre outros. Para formar uma comunidade política, a Europa não poderia entender-se apenas como uma comunidade econômica, uma vez que o acordo intergovernamental de Maastricht ${ }^{13}$ não teria força simbólica de fundação política.

a) Argumentos favoráveis para a continuidade do projeto da União Europeia (versão "ofensiva" da terceira via). A Europa deveria perseguir o objetivo de uma união cada vez mais estreita? Por quê? Argumentos capazes de justificar o objetivo político de uma constituição europeia federalista que ultrapassa os limites de uma simples confederação.

a.1) Em vista dos objetivos/interesses: (razões para uma integração mais forte). Os objetivos hoje se orientam por uma nova agenda, não tanto a preocupação com segurança e paz ou ainda com a política externa (a formação de uma superpotência global), mas sim com a união econômica (mercado comum europeu). No entanto, mesmo diante das expectativas de ganho no campo econômico, estas não constituem motivo suficiente capaz de levar os cidadãos a apoiar politicamente (conferindo legitimidade) o projeto de uma união apenas monetária. Diante de expectativas de crise/perda de eficiência (ameaças às garantias materiais de vida), a busca por uma Constituição parecia ser a resposta histórica para resolução dos problemas de eficiência econômica. No entanto, acentua Habermas, plebiscitos já demonstraram a falta de entusiasmo em abrir mão dos direitos conquistados no âmbito do Estado nacional em favor de instâncias europeias. Para além da insatisfação com os motivos meramente econômicos, estes motivos precisam ligar-se a uma ideia diferente capaz de convencer maiorias nacionais a se engajarem num projeto de transformação do status quo político, capaz de conservar no âmbito pós-nacional uma forma de vida sociocultural específica (um modelo de sociedade) consolidada nos Estados nacionais, mas que agora encontrase ameaçada.

Independente de como se interpreta a globalização econômica, ela não é resultado intrínseco de uma evolução natural. Se ela é resultado de decisões políticas intencionais, também seria possível, senão eliminar, ao menos amenizar os efeitos colaterais não-intencionais, não através de uma inversão do processo, mas através de políticas sociais e econômicas adicionais. É possível compensar a falta de emprego com investimentos em formação e reeducação, ou ainda programas de redistribuição de renda. Para Habermas, trata-se de uma decisão política sobre a extensão de um patamar apropriado de bem-estar, que depende de reflexões sobre justiça social e sobre experiências de solidariedade cidadã lesada. Isso não é inteiramente fora de propósito, 
considerando que nos países europeus se desenvolveu uma tradição política de solidariedade social oriunda do movimento dos trabalhadores, das doutrinas sociais da igreja e do liberalismo social. A cidadania democrática orienta-se por objetivos de políticas sociais inclusivas. Trata-se de um padrão de valores que combina, de forma inédita, individualismo privado e coletivismo público.

Nesse sentido, pergunta Habermas, de que modo a globalização econômica atinge o espaço de ação dos governos nacionais? Os Estados de bem-estar ainda seriam viáveis numa economia globalizada? Os governos nacionais não teriam mais condições do que a burocracia de Bruxelas para implementar programas compensadores? Não existe um nexo óbvio entre globalização dos mercados e uma gradual perda de autonomia dos Estados, responde Habermas. Mesmo com a coação da competição a nível mundial, parece que os Estados nacionais ainda contam com boas alternativas no âmbito político capazes de condicionar de modo direto a conjuntura dos níveis de emprego e segurança social ${ }^{14}$.

Para dar conta dos efeitos sociais colaterais da globalização econômica, Habermas se utiliza do recurso de uma "tradição política europeia", mais inclinada para a justiça social. Esta "cosmovisão" seria diferente da neoliberal que "não é muito bem adequada à autoconsciência normativa dos europeus"15. Ao avaliarem os efeitos colaterais das desigualdades sociais, os europeus teriam uma leitura (diferente do neoliberal) da proposta da União Europeia:

Na medida em que os europeus avaliam as consequências sociais indesejáveis das desigualdades distributivas crescentes e tentam influir, de certo modo, numa nova regulamentação da economia mundial, eles também têm que ter um interesse no poder de configuração política que uma União Europeia poderia desenvolver no círculo dos global players. ${ }^{16}$

Nesse caso, os valores da justiça e da solidariedade social, típicos da tradição política europeia, servem aqui como critérios justificadores da necessidade de influência política no projeto neoliberal de desregulação econômica dos mercados. Escreve Habermas:

Com respeito ao futuro de uma sociedade mundial altamente estratificada, nós, europeus, temos um interesse legítimo em fazer valer nossa voz num concerto internacional, que, até agora, interpretou a música seguindo uma partitura totalmente diferente. ${ }^{17}$

Para corrigir a condução da economia mundial não seria suficiente apenas aumentar a capacidade de ação política, mas sim, seria necessário desenvolver uma Europa institucionalmente forte, orientada e capaz de agir politicamente.

a.2) Problemas com os quais somos confrontados hoje em consequência de decisões já tomadas. É preciso resolver certos problemas oriundos de decisões políticas passadas. Outros argumentos que propõem uma continuidade do projeto europeu.

A ampliação da União Europeia, decorrente da inclusão de mais países em 2004, muito diferentes do ponto de vista social e econômico, provocou um problema estrutural, tornando o processo de regulamentação e cotação mais heterogêneo e complicado. Isso requer uma reforma estrutural capaz de dar conta da desproporção entre densas relações econômicas e políticas, bem como da deficiência democrática dos processos de decisão de Bruxelas.

Embora os Estados-membros tenham mantido os compromissos e obrigações no âmbito educacional, cultural, político-social e econômico-financeiro, no entanto, cederam sua autonomia e autoridade monetária para a instituição não-política do Banco 
Central Europeu, abrindo mão de um importante mecanismo de regulação. Não obstante, uma vez alcançado o equilíbrio e a estabilidade econômica, falta, entretanto, uma articulação uniformizadora das políticas sociais. Considerando que os Estados nacionais se orientam por tradições jurídicas, regimes sociais e políticos e sistemas de impostos distintos, os mesmos comportam-se de modo distinto a estímulos e desafios semelhantes. Por isso, alguns governos ainda estão em busca do melhor caminho para adaptar seus sistemas de seguridade social ao novo contexto econômico mundial, e, ao mesmo tempo, garantir padrões sociais mínimos.

Em contrapartida, a discrepância entre a integração econômica e a integração política poderia ser superada, defende Habermas, através de uma política que organiza competências de ação num nível superior. Para dar conta disso sob a forma de um "projeto europeu", os governos nacionais tentam recuperar em Bruxelas a capacidade reguladora e intervencionista perdida no seu próprio domínio.

No entanto, a recusa provisória de alguns países em se juntar à União Europeia demonstra, além de uma insatisfação política, também um déficit democrático das decisões que emergem do centro coordenador de Bruxelas ${ }^{18}$. Até aqui, as decisões das comissões e colegiados foram legitimadas por acordos intergovernamentais. No entanto, se esta forma de exercício do poder era suficiente enquanto se gerava políticas de mercado, agora, num contexto de acentuada crise econômica, seria preciso transcender os limites da mera coordenação econômica em vista de novos domínios políticos que consigam intervir positivamente em questões de distribuição de forma mais equitativa. Não obstante, é nesse nível que o problema da solidariedade civil no âmbito europeu aparece destacadamente. Avaliações mostram que mais da metade das decisões legislativas tomadas e implementadas a partir da burocracia de Bruxelas não são expostas à discussão pública nos Estados nacionais. Essa intransparência na origem das decisões que atingem a todos e a ausência de chances para os cidadãos europeus se integrarem aos processos de decisão são alguns dos motivos do ceticismo de amplas camadas da população.

b) Sobre as chances da União Europeia se transformar num Estado. A Europa pode preencher as condições empíricas necessárias para a nova configuração de um Estado composto de Estados nacionais? Quem seria capaz de implantar tal projeto (responsável(is) pela implantação), quando a população se opõe? Quais meios institucionais estariam à disposição?

De acordo com Habermas, os céticos não acreditam que as sociedades europeias atuais possam vir a preencher as condições necessárias para uma União Europeia de estrutura federalista porque não existiria uma identidade coletiva ou algo que poderia ser chamado de "povo europeu". A ausência de um sujeito coletivo "povo" capaz de se constituir como uma nação de cidadãos e amparar um processo constitucional democrático; não haveria um demos. Em contrapartida, Habermas recorre a grande conquista do Estado nacional democrático, a capacidade de integrar social e democraticamente, através do status de cidadania, uma solidariedade entre cidadãos, estranhos entre si, na ideia de nação de cidadãos. Esta solidariedade cidadã torna-se o novo cimento das sociedades nacionais. Nesse percurso, o que Habermas quer destacar é o caráter artificial do surgimento histórico das novas formas de identidade nacional, um processo de abstração capaz de convencer as pessoas a suspender a consciência local em favor de uma consciência de cidadãos democráticos que pertencem a uma nação. Esta é a crítica de Habermas aos céticos: "Se isso é verdade, então não há nenhuma razão para se pensar que a formação da solidariedade cidadã teria que ficar dentro dos limites do Estado nacional"19.

Dentre os pressupostos funcionais básicos a serem preenchidos para que uma tal 
formação da identidade possa se estender para além das fronteiras nacionais e a organização de uma estrutura democrática, Habermas destaca a exigência de uma cidadania europeia, a construção de uma esfera pública política europeia e a formação de uma cultura política compartilhada. Estes três elementos poderiam ser catalisados numa Constituição. A Europa deveria aplicar sobre si o mesmo processo dentro do qual nação e Estado democrático se gestaram mutuamente.

Sobre os atores da sociedade de cidadãos. Após a cobrança própria de impostos e a autonomia financeira, assumida a função de governo pela Comissão e Conselho Europeu, o Parlamento de Estrasburgo deveria estar em condições de aplicar imediatamente competências e atrair mais atenção. O eixo da política, bem como o trabalho dos partidos políticos, as atividades de grupos de interesse, sociedades econômicas e corporações profissionais, de organizações culturais e científicas, se deslocaria para Bruxelas (na Bélgica) e Estrasburgo (na França). A difusão para além das fronteiras nacionais de interesses formariam uma sociedade civil europeia, bem como um sistema europeu de partidos políticos.

Uma esfera pública democrática europeia seria condição indispensável para eliminar as deficiências de legitimação democrática. Esta surge da dinâmica que envolve a formação informal da opinião das arenas de comunicação pública e os processos institucionalizados de deliberação. A esfera pública preencheria a função primordial de legitimidade do Estado democrático de direito que, até agora, só existe no interior dos Estados nacionais. (embora não se deva imaginar a esfera pública europeia como uma projeção ampliada das arenas nacionais; não deve ser uma sobreposição). Ele - Estado democrático de direito - ainda precisa ser construído quando as esferas públicas nacionais se abrirem umas às outras e se entrelaçarem. Meios de comunicação bilíngues (canais de TV, jornais) e o inglês como segundo idioma principal poderiam fornecer um modelo promissor, prenuncia Habermas.

Além disso, a constituição de uma esfera pública europeia, além de depender das contribuições dos atores da sociedade civil, dependeria também da inserção numa cultura política europeia comum. A Europa superou diversos conflitos, diante dos quais conseguiu reagir em forma de aprendizado, encontrando um enfoque equilibrado entre o universalismo igualitário e individualista, desenvolvendo instituições sociais e políticas. O pano de fundo histórico (cultura social e política) poderia servir como caminho para uma democracia pós-nacional, embasada no reconhecimento recíproco das diferenças culturais nacionais capaz de produzir formas cada vez mais abstratas de solidariedade entre estranhos. Esta "nova consciência" de comunidade europeia já se encontraria expressa na Carta dos Direitos da União Europeia ${ }^{20}$, que proclama um catálogo de direitos fundamentais que apontam para além da simples perspectiva econômica, incluindo também determinações sociais.

\section{O PERFIL POLÍtico difERENTE dA EUROPA. TraÇOS Distintivos DA IDENTIDADE EUROPEIA}

Qual é o perfil político da Europa? O que o distingue do perfil político norteamericano? Quais as novas responsabilidades políticas para além do eurocentrismo? Quais as chances de uma transformação efetiva do direito internacional e suas instituições? Quais as chances de uma nova concepção e prática da divisão de poderes estatais pela ONU? Qual o futuro das instituições do direito internacional e quais as novas tarefas para a Europa? 


\section{a) O que define a identidade europeia. Perfil político da Europa.}

$\mathrm{Na}$ segunda parte da obra $O$ ocidente dividido, originalmente publicada em 2004, Habermas pergunta sobre a voz da Europa na multivocidade de suas nações. No capítulo 3, aponta o 15 de fevereiro de 2003 como o sinal do nascimento de uma esfera pública europeia: uma onda coordenada de protestos contra a guerra americana no Iraque nas principais capitais europeias, como Berlim, Roma, Paris, Madri e Londres ${ }^{21}$. Estes eventos também teriam sido uma forma de protesto contra a política mentirosa dos EUA.

A alusão a essa data (15 de fevereiro) deveria lembrar as maiores demonstrações que já ocorreram em cidades como Londres, Madrid, Barcelona, Roma, Berlim e Paris desde o fim da Segunda Guerra Mundial. Essas demonstrações não foram uma resposta ao 11 de setembro, que moveu os europeus imediatamente a manifestações de solidariedade impressionantes. Antes, expressam a indignação furiosa e impotente de uma multidão bem diversa dos cidadãos, dos quais muitos até então não tinham saído às ruas. $\mathrm{O}$ apelo dos adversários da guerra voltava-se de forma inequívoca contra a política mentirosa e que fere o direito internacional de governos aliados ${ }^{22}$.

Não obstante, a eclosão da Guerra do Iraque manifestou também o fracasso de uma política externa europeia. Diferenças e contradições que aparecem especialmente nas posições controversas em relação aos EUA, à relevância do direito internacional e da ONU, os objetivos diferentes ("próprios interesses") dos países integrantes da União Europeia, entre outros. Trata-se, segundo Habermas, de uma clara falta de concordância em relação a uma política europeia comum. Em contrapartida, desafia Habermas, seria preciso aprovar uma colaboração mais intensiva de uma política europeia externa comum, de segurança e de defesa comum, sem separações. O núcleo europeu deveria demonstrar que também tem capacidade de ação no exterior ${ }^{23}$. Escreve Habermas:

A Europa precisa colocar seu peso na balança da esfera internacional e no âmbito da ONU para contrabalançar o unilateralismo hegemônico dos Estados Unidos. Deveria fazer valer sua influência, nas cúpulas da economia mundial e nas instituições das organizações do comércio mundial, do banco mundial, e do fundo monetário internacional através da configuração do design de uma política interna mundial ${ }^{24}$.

É manifesto que, até agora, a capacidade de expansão, influência e reforma, notadamente econômica, limitou-se ao âmbito da União Europeia. E, para piorar, a força propulsora da criação de uma área econômica comum encontra-se no limite, e sua capacidade reformuladora está esgotada. Em contrapartida, Habermas sugere, não apenas uma política que exija a extinção das barreiras à competição econômica, mas uma "política formadora" da vontade comum que dependa dos motivos, das orientações e das convicções de pertencimento político dos próprios cidadãos. Por isso, os cidadãos deveriam estender a solidariedade nacional para uma solidariedade de dimensão europeia. No entanto, nesse momento, a elaboração de um destino político europeu compartilhado só poderia emergir de um sentimento perturbador de desamparo ${ }^{25}$. Não obstante, mesmo que na Europa atual os regimes estatais de bem-estar social encontrem-se na defensiva, uma política de domesticação do capitalismo além fronteiras não pode ficar aquém dos padrões de justiça social que foram estabelecidos ${ }^{26}$. É nesse sentido que a Europa deveria posicionar-se como um ator influente no palco mundial, defender e fazer avançar, contra projetos concorrentes, uma ordem cosmopolita baseada no direito internacional. Escreve Habermas: 
Os europeus têm uma confiança relativamente grande no trabalho de organização e na capacidade de direção do Estado, ao passo que são céticos em relação à capacidade de rendimento do mercado. Têm um sentido aguçado para a "dialética do Esclarecimento", não alimentam em relação a progressos técnicos expectativas invariavelmente otimistas. Têm preferências pelas garantias de segurança do Estado de bem-estar social e por regulamentações solidárias. O lastro de tolerância em relação ao exercício da violência contra pessoas é comparativamente baixo (...) Só na Europa este sistema (partidário que surgiu com a Revolução Francesa) serve a uma competição ideológica, que submete as consequências social-patológicas da modernização capitalista a uma avaliação política contínua. Isso estimula a sensibilidade dos cidadãos para os paradoxos do progresso (...). Na Europa... estabeleceu-se um etos da luta por "mais justiça social", solidário e voltado para o atendimento igual a todos, contra um etos da justiça da produtividade, que admite desigualdades sociais gritantes (...). Uma sensibilidade aguçada para violações da integridade pessoal e corporal reflete-se, entre outras coisas, no fato de o Conselho Europeu e a União Europeia terem estabelecido a renúncia à pena de morte como condição para o ingresso ${ }^{27}$.

Considerando que a Europa se caracteriza por um perfil político diferente, os traços distintivos de uma identidade europeia - a precedência do Estado em relação ao mercado, a solidariedade em relação à produtividade, o ceticismo técnico, a consciência dos paradoxos do progresso, a rejeição do direito do mais forte, entre outros - parecem emergir principalmente de um contraste com os Estados Unidos:

Os Estados da Eurozone poderiam reunir suas participações no Fundo Monetário Internacional, no Banco Mundial e no Banco de Compensação Internacional, para fazer valer a sua influência em várias questões. Mas tampouco é o caso de dizer que não existe nenhuma alternativa racional à razão neoliberal do regime econômico mundial existente ou à interpretação pela qual é defendida em Washington $^{28}$.

\section{b) Contrapoder do núcleo europeu?}

A expressão "Núcleo Europeu" foi utilizada por Habermas numa entrevista sobre guerra e paz em 2003 para indicar os problemas internos de unificação política e a posição da Europa frente ao unilateralismo americano:

Núcleo europeu é, em primeiro lugar, uma expressão técnica que os especialistas em política externa da CDU (União Democrática Cristã) Schäuble e Lamers, introduziram nos anos 90 para lembrar, num momento em que o processo de unificação europeia havia estagnado novamente, o papel precursor dos seis membros fundadores da Comunidade Europeia (...). O "núcleo europeu" é uma resposta a ambos: à crescente polêmica interna com relação à finalidade do processo de unificação... e ao acirramento do conflito que vem de fora... $\mathrm{O}$ unilateralismo hegemônico do governo dos EUA exige que a Europa finalmente aprenda a falar com uma voz no âmbito da política externa ${ }^{29}$.

A diferença de características entre europeus do continente e anglo-saxões também é expressa nesta outra passagem:

Uma coisa é se os EUA, no rastro de uma tradição política admirável, desempenham o papel voltado instrumentalmente para os direitos humanos, do agente hegemônico que garante a ordem. Outra coisa é se compreendermos a transição precária da política do poder clássica para um estado cosmopolita como 
um processo de aprendizagem que deve ser levado a cabo em conjunto. A perspectiva mais abrangente exige maior cautela. A autoconcessão de poder da OTAN não pode se tornar uma regra ${ }^{30}$.

Para Habermas, a autoridade normativa e a reputação que os EUA conquistaram como precursores de uma política global de direitos humanos está arruinada ${ }^{31}$. Mas um "contrapoder europeu" está longe de se materializar, observadas no âmbito europeu as enormes dificuldades em ir além da integração econômica. Se, por um lado, a série de protestos e eventos políticos de fevereiro de 2013 ativou uma solidariedade civil numa esfera pública europeia, por outro lado, as diferentes posições dos Estados-membros diante das intervenções americanas nas guerras do Iraque, Afeganistão, Kosovo, demonstram a falta de consenso em torno de uma "unificação política" europeia (que vá além da integração econômica). Nesse sentido, se foi possível criar uma integração econômica, também deveria ser possível uma integração política; se foi possível articular uma política fiscal, também deveria ser possível harmonizar diferentes regimes de política social. Entretanto, esta nova forma de integração - a integração política -, torna-se mais desafiadora porque mexe com as bases do modelo econômico liberal (base da integração econômica europeia), está associada a uma nova redistribuição (base da política social). Tal problema - da redistribuição ou domesticação do capitalismo - apenas poderia ser resolvido numa compreensão política ampliada que visa inserir todos os cidadãos europeus numa entidade política comum. Isso só seria possível estendendo a solidariedade estabelecida nas esferas nacionais para uma consciência de cidadania comum europeia. Talvez as manifestações de fevereiro de 2013 por toda a Europa tenham sido indicadores dessa consciência, pressagia Habermas.

Nessa perspectiva, apenas seria possível resolver os problemas de integração política da união europeia expandindo para o âmbito europeu um "patriotismo constitucional", que, no entanto, ainda precisaria ser construído. A passagem de uma solidariedade abstrata entre cidadãos de um Estado que ultrapassa os âmbitos locais não teria surgido do nada, mas sim se desenvolvido com a formação dos Estados nacionais. Nesse sentido, seria preciso ampliar essa solidariedade para além das fronteiras nacionais, criando uma solidariedade abstrata entre europeus. No entanto, alerta Habermas, a persistência absurda de egoísmos nacionais seria uma das principais dificuldades em se aprovar uma Constituição da União Europeia a partir de Bruxelas. Faltaria um acordo em relação a finalidade do processo de unificação europeia como um todo, se deveria ser apenas uma área de livre comércio ou também se tornar um ator político influente. Faltaria também aprofundar a reforma das instituições políticas de modo a garantir uma composição e representação mais adequada, denuncia Habermas.

Diante dos problemas atuais do processo de unificação política, tais como os desafios da ampliação para o leste, as consequências políticas da integração econômica para os países da Eurozone e a transformação da situação política mundial, a Europa vêse desafiada a redefinir seu papel global, especialmente diante do fim de uma ordem mundial bipolar e da emergência do unilateralismo norte-americano. Assim, além das dificuldades da falta de uma identidade política europeia forte, também as dificuldades de elaboração de políticas de segurança e de defesa convergentes mostram o quanto o processo de unificação europeia estaria paralisado ${ }^{32}$.

Também o recurso a uma solidariedade de cidadãos como fonte de legitimação da integração aos moldes da ONU parece não ser a solução para Habermas. A ONU se orienta por uma base de legitimação fraca: da política dos direitos humanos, garantia da paz; um potencial de integração fraco. A solidariedade dos cidadãos pode ser despertada pela indignação moral (reação afetiva) em relação a violação do uso da força e dos 
direitos humanos (por exemplo, atos de criminalidade de massa). No entanto, esse potencial fraco é insuficiente para a União Europeia, que precisa de uma integração forte, afirmativa. $\mathrm{O}$ potencial de solidariedade não pode ser produzido a partir de reações negativas de uma moral universal de justiça (no caso da ONU). Esse ethos político também não brota naturalmente, precisa apresentar-se e realizar-se como algo construído. Por isso, é preciso criar mecanismos e procedimentos que fortaleçam o sentimento de pertencimento dos cidadãos como membros de uma mesma comunidade política $^{3} 3$. Por isso, mais importante do que está dado (um sujeito ou um povo europeu), é saber o que pode ser construído.

A questão, portanto, não é se existe uma identidade europeia, mas se as arenas nacionais podem se abrir umas para as outras, de tal modo que se desenvolva para além das fronteiras nacionais a dinâmica própria de uma formação política comum de opinião e vontade em torno de temas europeus (...). A estrutura de solidariedade entre cidadãos de um Estado não coloca empecilho à sua possível ampliação para além das fronteias nacionais. Por sinal, a confiança crescente não é apenas consequência de uma formação política comum de opinião e vontade, mas é também sua precondição $0^{34}$.

\section{O IMPASSE dA INTEGRAÇÃo POLÍTICA EUROPEIA. AusênCIA de POLÍTICA EXTERNA. DESAFIOS EXTERNOS}

Na obra Ach Europa, publicada em 2008, e traduzida como Europe. The faltering project pela Polity Press em 2009, Habermas continua, especialmente no capítulo 8, as intervenções sobre a situação europeia em torno do déficit democrático, da ausência de uma política externa da União Europeia, o progressivo enfraquecimento dos padrões sociais dignos que não pode ser resolvido isoladamente, a relação entre política e mercado que está desiquilibrada no âmbito global, e a necessidade de global players capazes de um novo equilíbrio entre sujeitos de direito numa economia global, bem como o agravamento fundamentalista do pluralismo cultural ${ }^{35}$.

\section{resposta.}

a) Exigências/desafios externos. A União Europeia precisa encontrar uma

Não apenas os problemas que se agravam na dinâmica interna do processo de unificação da União Europeia impelem para uma reorientação ofensiva com o dilema dos não resolvidos conflitos quanto aos objetivos. Também as exigências, pelas quais a Europa é exposta ao mundo, reclamam uma decisão entre a alternativa da aceitação de uma progressiva delegação de poder e a decisão de uma continuada integração. É preciso saber se a Europa deve apenas assumir o até agora papel reconhecidamente principiante no palco da política mundial ${ }^{36}$.

$\mathrm{O}$ declarado unilateralismo dos Estados Unidos, desde o anúncio da doutrina Bush no outono de 2002, da seletiva marginalização das Nações Unidas, da invasão do Iraque, da progressiva agressão do humanitário direito das gentes e uma indisfarçável política double standards, dois pesos e duas medidas, tem destruído a credibilidade dos fundamentos normativos da política ocidental. Na perspectiva de uma nova ordem mundial, trata-se de uma política de poder que desencadeou uma implacável perseguição dos interesses nacionais. No entanto, na eclosão do conflito entre Israel e Líbano, em vez de apresentarem uma posição europeia enfática e conjunta sobre a política externa, ao contrário, países como Alemanha, França, Itália e Espanha e GrãBretanha se posicionaram cada um a seu modo e de acordo com seus interesses. Nesse sentido, torna-se necessária uma reavaliação institucional da Comissão Europeia para 
uma política externa e de segurança comum ${ }^{37}$.

Dois são os argumentos do porquê esta região economicamente significativa deveria trabalhar mais fortemente a voz política (politische Gehör verschaffen):

Primeiro. Os Estados nacionais sozinhos quase não têm mais chance de lidar cada um por si com a influência da política mundial ${ }^{38}$. Na transição para uma constelação pós-nacional, é inegável a diminuição da capacidade de ação dos Estados nacionais. A soberania dos sujeitos de direito internacional, do direito elementar que decide sobre guerra e paz, não apenas se tornou apenas formal, como também encolheu. Os Estados nacionais perderam em grande parte, em âmbitos funcionais que antes ainda podiam decidir de forma mais ou menos independente da globalização, uma parte significativa da sua capacidade de controle, como a garantia da paz, da liberdade, garantia jurídica e legitimação democrática. Desde o fim do capitalismo de estado e o deslocamento da relação entre política e mercado para mercados globalizados, o Estado também é atingido de forma mais drástica no seu papel de Estado-intervencionista. Por exemplo, a segurança física no seu próprio território já não é garantida sem um trabalho internacional em conjunto contra os riscos da tecnologia, a ampliação das epidemias, as redes de terrorismo ou os fluxos migratórios. Até os sistemas jurídicos perderam parte da eficácia em virtude de decisões jurídicas no âmbito internacional. Os procedimentos nacionais de formação de opinião e de controle são muito fracos para cobrir a necessidade de legitimação que surge com as repercussões locais de regulamentos internacionais. A desregulamentação dos mercados, especialmente dos mercados financeiros, limita o âmbito de intervenção dos governos nacionais e retira sua capacidade de controle fiscal de suas empresas mais bem sucedidas ${ }^{39}$. Em vista dessa nova dependência, os Estados nacionais podem tentar se adaptar mais ou menos a constelação pós-nacional. Os estados nacionais podem compensar sua função ao se juntarem como parceiros globais nas redes internacionais existentes. Até agora, se delinearam duas formas típicas de "governar em âmbitos ilimitados" (regieren in entgrenzten Räumen). Os Estados nacionais organizam sua representação e tentam influenciar individualmente a agenda e capacidade de negociação em organizações multilaterais na formação de blocos (p. ex.: G8, G20) ou se juntam com seus Estados vizinhos e organizam alianças regionais (regionalen Bündnissen) para somar e mobilizar sua forma e permanência. A União Europeia em comparação com ambos os casos (como a Associação das Nações do Sudeste Asiático ou União Africana) seria o melhor exemplo para uma tal forma de governo supranacional e, nesse sentido, um modelo para esforços parecidos na América Latina, Ásia e África.

Segundo. Em sociedades multiculturalmente divididas e sistematicamente diferenciadas não há perspectivas (keine Aussicht) de uma desejada institucionalização transnacional de uma política interna mundial se os Estados nacionais pequenos e médios não se juntarem em regimes regionais com capacidade de ação e negociação global, a exemplo da União Europeia. Hoje os problemas globais se impõem de tal modo que quase não podem ser resolvidos sem aquela forma supranacional de blocos regionais, especialmente em relação aos problemas de segurança nacional, a provisão (Vorsorge) global contra o desequilíbrio ecológico (mudança climática, fornecimento de água tratada), a distribuição dos escassos recursos energéticos, a implantação dos direitos humanos elementares, e uma ordem econômica justa capaz de superar a distribuição desigual das chances de vida e além de ajudar zonas de catástrofe e miséria. Do ponto de vista da magnitude desses problemas, Habermas se pergunta pelo âmbito institucional mais apropriado no qual eles poderiam ser tratados (bearbeiten). Enquanto alguns problemas podem ser resolvidos no âmbito das fronteiras nacionais, Habermas não consegue imaginar como os outros problemas poderiam ser resolvidos sem uma 
reforma da base das Nações Unidas e a implementação de uma institucionalizada política interna mundial ${ }^{41}$.. A ridícula desproporção entre o esvaziamento da cúpula do G-8 e as exaltadas crescentes expectativas, que se fixam neste simbólico evento esvaziado, tanto nos meios de comunicação públicos como nas cenas de protesto, é um significativo sintoma para uma alargada consciência do que falta:

Falta um comitê de negociação transnacional (transnationales Verhandlungsgremium) composta de modo suficientemente representativo, e de modo justo negociar compromissos de superação de problemas globais bem como implementá-los nas respectivas regiões ${ }^{42}$.

As organizações multilaterais já existentes seriam seletivas e apenas jogariam a assimetria das relações de poder (Machtverhältnisse) existentes. Apenas quando aquela lacuna fosse preenchida, poderia se falar em governos para além dos Estados nacionais. Apesar de alguns Estados nacionais poderem ser mais ou menos bem-sucedidos no incremento de uma teia de organizações e redes internacionais, o poder de negociação (Verhandlungsmacht) e o potencial de ameaça de Estados individuais seriam insuficientes quando se trata de um arranjo inovador de uma ordem internacional que lida com problemas globais. O peso político de uma capacidade de ação e negociação da União Europeia de política externa é, no entanto, não apenas necessário para o árduo caminho de construção de uma nova ordem mundial. Tal União é apenas uma necessidade funcional para a bem-sucedida operação de uma sociedade mundial constituída politicamente ${ }^{43}$.

Diante deste quadro, a expansão de uma união política europeia não oferece um caminho operativo capaz de resolver os impasses atuais. Na verdade, trata-se de um diagnóstico correto das razões do problema: o aspecto político não apareceu na elaboração da Constituição europeia em virtude da ênfase na econômica da integração. Esse equívoco pode ser notado nos referendos, processos de ratificação e pesquisas, cujos resultados refletem um quadro bem diferente. De acordo com Habermas, o Tratado de Lisboa não estaria tão distante da configuração de uma democracia transnacional; a falha na construção da união monetária não pode ser remediada sem uma alteração do Tratado, e exige uma ampliação da base de legitimação ${ }^{44}$. Por isso, é inevitável a reforma da Constituição política da União Europeia como condição para desenvolver uma política de integração gradual.

É nesse sentido que se dirigem as críticas de Habermas às reações europeias à crise de integração: à relutância do governo alemão em relação à Europa e sua percepção etnocêntrica e autocentrada ${ }^{45}$; ao "pacto dela Europa" organizado por chefes de Estado em 2011 e que interfere no âmago dos parlamentos nacionais (tipo de política denominado por Habermas de "federalismo executivo": modelo de um exercício de dominação "pós-democrático", responsável pelo esvaziamento intergovernamental da democracia ${ }^{46}$; ao retraimento das elites políticas, preocupadas apenas na manutenção do poder, que se tornaram meramente uma elite funcional, incapaz de resolver o problema, pois isso exigiria uma outra forma de fazer política. Por isso, a tentativa de Habermas de tirar do caminho certos bloqueios mentais que ainda persistem a respeito de uma transnacionalização da democracia ${ }^{47}$.

Esta seria a maior fraqueza da integração europeia até aqui: a visível incapacidade para uma política econômica comum, não havendo uma ideia comum nem sequer em torno de uma política econômica, uma vez que na crise cada governo resolveu reagir individualmente, com medidas próprias de política econômica, com cada país exercendo sua própria política externa ${ }^{48}$, recaindo nos velhos jogos de poder entre Estados. Por isso, alerta Habermas, da necessidade de uma colaboração mais 
aproximada dos Estados-membros, ou continuar a ter peso irrelevante na política mundial:

A "cooperação mais estreita" no âmbito da política econômica teria que ser seguida de uma cooperação semelhante na política externa. E ambas não poderiam ser novamente negociadas desconsiderando a vontade das populações ${ }^{49}$.

Apenas coletivamente os países do euro poderiam obter um peso na política mundial que lhes permita influir racionalmente sobre a agenda da economia mundial. Do contrário, eles se apresentam como poodles do Tio Sam em uma situação mundial tão perigosa quanto caótica ${ }^{50}$.

Para concluir, destaca-se ainda uma lacuna peculiar na integração europeia entre a formação da vontade e da opinião política dos cidadãos e a solução dos atuais problemas que os políticos seguem. De acordo com Habermas, as principais instituições criadas - Banco Central Europeu, Comissão Europeia, Conselho e Parlamento Europeus - embora presente no cotidiano dos cidadãos, ao mesmo tempo imputaram-se o controle democrático. Até hoje, opiniões informadas e comentários calculados no curso do desenvolvimento europeu permaneceram amplamente assunto de políticos profissionais, elites econômicas e interessados cientistas, não de intelectuais. Isso geraria uma imagem confusa para os cidadãos sobre a finalidade da União Europeia e seu futuro. Ironicamente, o que hoje aproxima os cidadãos europeus são as vozes eurocéticas, que por diferentes motivos se reforçaram em todos os países membros no decurso da crise, o que evidencia ainda mais uma "política europeia desacoplada" (entkoppelte Europapolitik) $^{51}$.

\section{REFERÊNCIAS}

HABERMAS, Jürgen. A constelação pós-nacional: ensaios políticos. Trad. Márcio SeligmannSilva. São Paulo: Littera Mundi, 2001. [orig. Die postnationale Konstellation. Frankfurt: Suhrkamp, 1998].

. Era das transições. Trad. Flávio Siebeneichler. Rio de Janeiro: Tempo Brasileiro, 2003. [orig. Zeit der Übergänge. Frankfurt: Suhrkamp, 2001]

. O Ocidente dividido. Trad. Luciana Villas Bôas. Rio de Janeiro: Tempo Brasileiro, 2006. [orig. Der gespaltene Westen. Frankfurt: Suhrkamp, 2004] . Ach Europa. Frankfurt: Suhrkamp, 2008. [Trad. ingl. Ciaran Cronin: Europe: the faltering project. Cambridge/UK: Polity Press, 2009]. Zur Verfassung Europas: Ein Essay. Berlin: Suhrkamp, 2011.

Sobre a constituição da Europa: um ensaio. Trad. Denilson Werle, Luiz Repa e Rúrion Melo. São Paulo: Unesp, 2012.

Im Sog der Technokratie. Berlin: Suhrkamp, 2013. [Trad. de Luiz Repa: Na esteira da tecnocracia: São Paulo: Unesp, 2014]

LUBENOW, Jorge A. The paradox of technocratic democracy and the democratic deficit of european institutions by Jürgen Habermas. Aufklärung: Revista de Filosofia, v. 2, n. 2, 2015, p. 103-122. Disponível em: http://dx.doi.org/10.18012/arf.2016.25907

. A redefinição do perfil político da Europa de estatal-social para econômico-liberal: uma análise crítica a partir de Jürgen Habermas. Aufklärung: Revista de Filosofia, v. 3, n. 2, 2016, p. 83-100. Disponível em: http://dx.doi.org/10.18012/arf.2016.30972

\section{Notas}

1 HABERMAS, Jürgen. Ach Europa. Frankfurt: Suhrkamp, 2008, prefácio, p. 7 
2 HABERMAS, Jürgen. Zur Verfassung Europas. Berlin: Suhrkamp, 2011, cap. 3, p. 109-111.

3 Cf. HABERMAS, Jürgen. A constelação pós-nacional: ensaios políticos. São Paulo: Littera Mundi, 2002, cap. 4, p. 113-114.

4 Cf. HABERMAS, A constelação pós-nacional, cap. 4, p. 125.

5 Cf. HABERMAS, A constelação pós-nacional, cap. 4, p. 127.

6 Cf. HABERMAS, A constelação pós-nacional, cap. 4, p. 129.

7 HABERMAS, Jürgen. Era das transições. Rio de Janeiro: Tempo Brasileiro, 2003, prefácio, p. 17.

8 Cf. HABERMAS, Era das transições, cap. 1, p. 28.

9 HABERMAS, Era das transições, cap. 1, p. 29.

10 Sobre como essas posições aparecem no debate político europeu (e também dos partidos políticos nacionais), ver: HABERMAS, Era das transições, cap. 6, p. 118-119, as indicações bibliográficas e nota de rodapé.

11 Cf. HABERMAS, Era das transições, cap. 6, p. 120.

12 HABERMAS, Era das transições, cap. 6, p. 121.

13 Tratado da União Europeia (também chamado de Tratado de Maastricht) assinado na cidade de Maastricht (Holanda), em 7 de fevereiro de 1992 e entrando em vigor em 01 de janeiro de 1993. Com a entrada em vigor deste Tratado, a Comunidade Econômica Europeia (CCE) torna-se Comunidade Europeia (CE). Os poderes legislativo e de controle do Parlamento Europeu reforçam-se com a introdução do processo de co-decisão e com o alargamento do processo de cooperação. Posteriormente, foi alterado pelo Tratado de Amsterdã (1997) e pelo Tratado de Nice (2002). Sobre os tratados da União Europeia, ver:

http://www.europarl.europa.eu/aboutparliament/pt/00b82c7869/Os-Tratados-e-o-ParlamentoEuropeu.html

14 Cf. HABERMAS, Era das transições, cap. 7, p. 131.

15 HABERMAS, Era das transições, cap. 7, p. 132.

16 HABERMAS, Era das transições, cap. 7, p. 132-133.

17 HABERMAS, Era das transições, cap. 7, p. 133.

18 O Tratado que estabeleceria uma Constituição Europeia foi assinado em Roma (Itália) em 29 de outubro de 2004. Depois de aprovado pelo Parlamento Europeu, não entrou em vigor pois não foi ratificado por todos os Estados-Membros, sendo rejeitado, em referendos nacionais, pela França (29 de maio de 2005) e pela Holanda (1 de junho de 2005). Na sequência das dificuldades de ratificação verificadas em certos Estados-Membros, os Chefes de Estado ou de Governo decidiriam, em junho de 2005, lançar um "período de reflexão" sobre o futuro da Europa, que deveria permitir iniciar um amplo debate com os cidadãos europeus. Em contrapartida, foi elaborado e assinado um "tratado reformador", denominado de Tratado de Lisboa (2007), assinado em 13 de dezembro de 2007 e entrando em vigor em janeiro de 2009, com o objetivo de reforçar a eficiência e a legitimidade democrática. Sobre isso, ver: http://europa.eu/scadplus/constitution/introduction_pt.htm

19 HABERMAS, Era das transições, cap. 7, p. 138.

20 Assinada em Nice (França), em 7 de dezembro de 2000 e alterada em 12 de dezembro de 2007, em Estrasburgo (França). Disponível em: http://www.europarl.europa.eu/charter/default_pt.htm

21 Cf. HABERMAS, Jürgen. $O$ ocidente dividido. Rio de Janeiro: Tempo Brasileiro, 2006, cap. 3 , p. 44.

22 HABERMAS, $O$ ocidente dividido, cap. 7, p. 91.

23 Cf. HABERMAS, $O$ ocidente dividido, cap. 3, p. 45-46

24 HABERMAS, $O$ ocidente dividido, cap. 3, p. 46.

25 Cf. HABERMAS, $O$ ocidente dividido, cap. 3, p. 46-47.

26 Cf. HABERMAS, $O$ ocidente dividido, cap. 3, p. 47-48.

27 HABERMAS, $O$ ocidente dividido, cap. 3, p. 50-52.

28 HABERMAS, $O$ ocidente dividido, cap. 3, p. 60.

29 HABERMAS, $O$ ocidente dividido, cap. 7, p. 92-93. 
30 HABERMAS, $O$ ocidente dividido, cap. 7, p. 89.

31 Cf. HABERMAS, $O$ ocidente dividido, p. 34, 53.

32 Sobre as causas do atraso da unificação política europeia, ver meus artigos: LUBENOW, A redefinição do perfil político da Europa de estatal-social para econômico-liberal: uma análise crítica a partir de Jürgen Habermas. Aufklärung: Revista de Filosofia, v. 3, n. 2, 2016, p. 83-100; LUBENOW, The paradox of technocratic democracy and the democratic deficit of european institutions by Jürgen Habermas. Aufklärung: Revista de Filosofia, v. 2, n. 2, 2015, p. 103-122.

33 Cf. HABERMAS, $O$ ocidente dividido, cap. 6, p. 83-84.

34 HABERMAS, $O$ ocidente dividido, cap. 6, p. 84.

35 Cf. HABERMAS, Jürgen. Ach Europa. Frankfurt: Suhrkamp, 2008, cap. 8, p. 91-92.

36 Cf. HABERMAS, Ach Europa, cap. 9, p. 108.

37 Cf. HABERMAS, Ach Europa, cap. 9, p. 109-110.

38 Embora certa literatura sobre o tema seja mais ou menos unânime em afirmar que, apesar das interconexões de instituições e organismos internacionais, os grandes estados nacionais ainda seriam atores importantes no nível global; e de que no nível global ainda não seria possível encontrar equivalentes funcionais competentes de resolução coletiva de conflitos ou detentores do direito ou poder político.

39 Cf. HABERMAS, Ach Europa, cap. 9, p. 111-112.

40 Cf. HABERMAS, Ach Europa, cap. 9, p. 112-113.

41 Cf. HABERMAS, Ach Europa, cap. 9, p. 114.

42 HABERMAS, Ach Europa, cap. 9, p. 114.

43 Cf. HABERMAS, Ach Europa, cap. 9, p. 114-115.

44 Cf. HABERMAS, Jürgen. Sobre a constituição da Europa. São Paulo: Unesp, 2012, prefácio, p. 3.

45 Cf. HABERMAS, Sobre a constituição da Europa, Prefácio, p. 1-6; ver tb. Parte III - A Europa na Alemanha, cap. 3.1 - Depois da bancarrota: uma entrevista, p. 109; e 3.2 - O euro decide o destino da União Europeia, p. 125.

46 Cf. HABERMAS, Sobre a constituição da Europa, prefácio, p. 2.

47 Cf. HABERMAS, Sobre a constituição da Europa, prefácio, p. 4.

48 Cf. HABERMAS, Sobre a constituição da Europa, cap. 3, p. 121.

49 HABERMAS, Sobre a constituição da Europa, cap. 3, p. 122.

50 HABERMAS, Sobre a constituição da Europa, cap. 3, p. 122.

51 Cf. HABERMAS, Jürgen. Im Sog der Technokratie. Berlin: Suhrkamp, 2013, cap. 5, p. 82-83. Sobre o tema da política tecnocrática, ver: LUBENOW, 2015, 2016. 